\title{
A Hybrid Genetic Optimization Method for Accurate Target Localization
}

\author{
Maja Rosic ${ }^{1)}$ \\ Mirjana Simić ${ }^{2)}$ \\ Predrag Pejović ${ }^{2)}$
}

\begin{abstract}
This paper considers the problem of estimating the position of a target based on the time of arrival (TOA) measurements from a set of receivers whose positions are known. The weighted least square (WLS) technique is applied as an efficient existing approach. The optimization problem is formulated by the minimization of the sum of squared residuals between estimated and measured data as the objective function. The hybrid Genetic Algorithm-Nelder-Mead (GA-NM) method is proposed that combines the global search and local search abilities in an effective way in order to improve the performance and the solution accuracy. The corresponding Cramer-Rao lower bound (CRLB) on the localization errors is derived as a benchmark. Simulation results show that the proposed hybrid GA-NM method achieves a significant performance improvement compared to existing methods
\end{abstract}

Key words: receiver, localization, optimization, genetic algorithm, hybrid method.

\section{Introduction}

$\mathrm{T}$ HE problem of finding the unknown location of a target based on TOA measurements from a set of receivers whose positions are known is a fundamental problem in many applications such as military target tracking, environmental monitoring, telecommunications, security systems and many others [1-2].

The localization algorithms use various techniques such as TOA, time difference of arrival (TDOA), received signal strength (RSS), or angle of arrival (AOA). The focus of the present paper is a target localization problem based on the TOA measurements due to its simplicity and efficiency.

The target location can be estimated based on the least squares (LS) and the maximum likelihood (ML) estimation techniques, as powerful methods which can be employed successfully in practical applications. Hence, the localization problem can be formulated as an optimization problem known as least squares that minimizes the sum of squared errors between the estimated and the measured distances.

In general, the LS problems can be divided into two categories: linear least squares (LLS) and nonlinear least squares (NLS). In this work, the NLS is applied to solve target localization problem based on the noisy TOA measurements. However, the objective function of the NLS estimation for the considered localization problem is a highly nonlinear and multimodal. Thus, obtaining the global optimal solution of NLS problem with classical optimization methods is a difficult task, as the convergence of these algorithms heavily depends on the selection of initial points and may not always converge to the global optimal solution. In order to overcome these difficulties and to provide highly accurate optimal solution, a new hybrid optimization procedure, which combines the Genetic Algorithm (GA) with a local direct search Nelder-Mead (NM) method is presented in this paper, due to their robustness and efficiency. The proposed hybrid GA-NM method is divided in two phases in the process of finding the optimal solution. During the first phase, the GA explores the search space in order to find promising regions in which the global optimal solution may lie and provide good initial solution for local direct search method. In the second phase, the solution from the first phase is used as a starting point for the local direct search NM method, which is able to simultaneously improve the solution quality and convergence speed of the algorithm.

The WLS technique is presented in this paper to estimate the target location due to its computational efficiency and closed-form solution [3]. This technique linearizes the nonlinear TOA measurement equations by introducing an additional variable in order to minimize the weighted sum of squared residual errors.

To compare the localization accuracy, the corresponding CRLB is derived, which provides a lower bound on the variance of any unbiased estimator [4].

The paper is organized as follows. The target localization problem based on the noisy TOA measurements from a set of receivers whose positions are known is reviewed in Section 2. Section 3 describes target localization problem which is modelled as a least squares estimation problem with NLS and WLS approaches. In Section 4, the hybrid GA-NM method is presented. The CRLB is given in Section 5. Section 6 gives the simulation results of the proposed hybrid GA-NM method against the WLS and the GA approaches. Finally, conclusions are drawn in Section 7.

\section{Problem formulation}

In this section, the two-dimensional (2-D) target localization model using noisy TOA measurements under the

\footnotetext{
1) University of Belgrade, Faculty of Mechanical Engineering, Kraljice Marije 16, 11020 Belgrade 35, SERBIA

2) University of Belgrade, School of Electrical Engineering, Bulevar kralja Aleksandra 73, 11000 Belgrade, SERBIA

Correspondence to: Maja Rosić; e-mail: mrosic@mas.bg.ac.rs
} 
line-of-sight (LOS) environment is presented. In order to estimate the true location of the unknown target $\mathbf{x}=[x, y]^{T}$, at least three receivers, $N \geq 3$, have to be placed on the known positions $\quad \mathbf{x}_{l}=\left[x_{l}, y_{l}\right]^{T}, \quad \forall l \in\{1,2, \ldots, N\}$, where $[\cdot]^{\mathrm{T}}$ denotes matrix transpose, as shown in Fig.1.

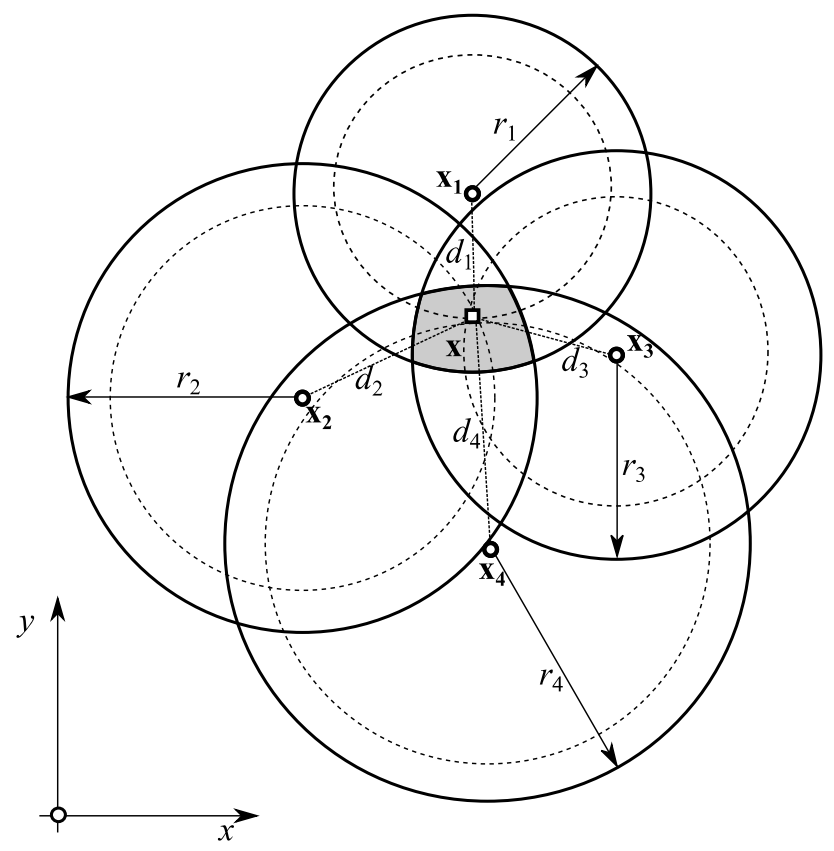

Figure 1. Illustration of the geometrical model based on the noisy TOA measurements

In the absence of measurement errors, the true coordinates of the target location at point $\mathbf{x}=[x, y]^{T}$ are obtained at the intersection of set circles, with radii $\left\{d_{l}\right\}$ and centres $\mathbf{x}_{l}=\left[x_{l}, y_{l}\right]^{T}, \forall l \in\{1,2, \ldots, N\}$, created around each receiver, as depicted in Fig.1.

It is assumed that the distance measurement errors $\left\{n_{l}\right\}$ are independent Gaussian random variables with zero mean and known variance $\sigma_{l}^{2}$, i.e., $\mathcal{N}\left(0, \sigma_{l}^{2}\right)$. In the presence of the measurement errors, three or more than three circles do not intersect at the same point, and they form the region inside of which the estimated target location can be found. Then, the distances $\left\{r_{l}\right\}$, between the target $\mathbf{x}$ and each receiver $\mathbf{x}_{l}$, based on the noisy TOA measurements $\left\{t_{l}\right\}$, are expressed as follows:

$$
\begin{aligned}
r_{l} & =c \cdot t_{l} \\
& =d_{l}+n_{l} \\
& =\sqrt{\left(x-x_{l}\right)^{2}+\left(y-y_{l}\right)^{2}}+n_{l}, \quad \forall l \in\{1,2, \ldots, N\}
\end{aligned}
$$

where $c$ is the propagation speed and $d_{l}$ is distance between the true target location and $l$ th receiver.

Thus, the Eq. (1) can be written in a vector form as:

$$
\mathbf{r}=\mathbf{d}(\mathbf{x})+\mathbf{n},
$$

where $\mathbf{d}(\mathbf{x})=\left[d_{1}, \ldots, d_{N}\right]^{T}$ is the vector of true distances and $\mathbf{n}=\left[n_{1}, \ldots, n_{N}\right]^{T}$ is a measurement noise vector.

\section{Least squares methods}

In this section, LS methods for a target localization based on the noisy TOA measurements are presented. This method is based on the minimization of the NLS objective function $J_{N L S}(\mathbf{x})$, which is defined as the sum of squared residuals between the estimated and the measured TOA values, i.e.:

$$
\min _{\mathbf{x} \in \mathrm{R}^{2}} J_{N L S}(\mathbf{x})=\min _{\mathbf{x} \in \mathrm{R}^{2}} \sum_{l=1}^{N} R_{l}^{2}(\mathbf{x}),
$$

where residual $R_{l}(\mathbf{x})$ is given by:

$$
R_{l}(\mathbf{x})=r_{l}-\sqrt{\left(x-x_{l}\right)^{2}+\left(y-y_{l}\right)^{2}} .
$$

Therefore, the problem defined in Eq. (3) is an unconstrained nonlinear optimization problem, where the optimal target location can be obtained as a minimum of the objective function $J_{N L S}$, that is:

$$
\hat{\mathbf{x}}=\underset{\mathbf{x} \in R^{2}}{\operatorname{argmin}} J_{N L S}(\mathbf{x}) .
$$

The nonlinear equations can be transformed into a set of linear equations through the following process.

Squaring the both sides of Eq. (1) yields:

$$
\begin{aligned}
& r_{l}^{2}=\left(x-x_{l}\right)^{2}+\left(y-y_{l}\right)^{2}+n_{l}^{2} \\
& +2 n_{l} \sqrt{\left(x-x_{l}\right)^{2}+\left(y-y_{l}\right)^{2}}, \forall l \in\{1, \ldots, N\} .
\end{aligned}
$$

Introducing the additional variables:

$$
R=x^{2}+y^{2},
$$

and

$$
m_{l}=n_{l}^{2}+2 n_{l} \sqrt{\left(x-x_{l}\right)^{2}+\left(y-y_{l}\right)^{2}} .
$$

then substituting Eqs. (7)-(8) into Eq. (9), yields:

$$
\begin{aligned}
r_{l}^{2} & =\left(x-x_{l}\right)^{2}+\left(y-y_{l}\right)^{2}+m_{l}, \\
& \Leftrightarrow r_{l}^{2}=x^{2}-2 x_{l} \cdot x+x_{l}^{2}+y^{2}-2 y_{l} \cdot y+y_{l}^{2}+m_{l} \\
& \Leftrightarrow-2 x_{l} \cdot x-2 y_{l} \cdot y+R+m_{l}=r_{l}^{2}-x_{l}^{2}-y_{l}^{2}, \\
\forall & \in\{1,2 \ldots, N\}
\end{aligned}
$$

Hence, Eq. (9) can be expressed in linear matrix form as follows:

$$
\mathbf{A} \boldsymbol{\theta}+\mathbf{m}=\mathbf{b},
$$

where

$$
\begin{aligned}
& \mathbf{A}=\left[\begin{array}{ccc}
-2 x_{1} & -2 y_{1} & 1 \\
-2 x_{2} & -2 y_{2} & 1 \\
\vdots & \vdots & \vdots \\
-2 x_{N} & -2 y_{N} & 1
\end{array}\right] \\
& \boldsymbol{\theta}=\left[\begin{array}{lll}
x & y & R
\end{array}\right]^{T}, \\
& \mathbf{m}=\left[\begin{array}{llll}
m_{1} & m_{2} & \cdots & m_{N}
\end{array}\right],{ }^{T} \\
& \mathbf{b}=\left[\begin{array}{c}
r_{1}^{2}-x_{1}^{2}-y_{1}^{2} \\
r_{2}^{2}-x_{2}^{2}-y_{2}^{2} \\
\vdots \\
r_{N}^{2}-x_{N}^{2}-y_{N}^{2}
\end{array}\right] .
\end{aligned}
$$


From Eqs. (10)-(14) respectively, the WLS objective function is defined as follows:

$$
J_{W L S}(\boldsymbol{\theta})=(\mathbf{A} \boldsymbol{\theta}-\mathbf{b})^{T} \mathbf{W}(\mathbf{A} \boldsymbol{\theta}-\mathbf{b}),
$$

where $\mathbf{W}=\left(E\left\{\mathbf{m m}^{T}\right\}\right)^{-1}$ is the weighting matrix. Thus, the unconstrained optimization problem can be formulated as follows:

$$
\min _{\mathbf{x} \in R^{2}} J_{W L S}(\boldsymbol{\theta}) .
$$

Hence, the goal is to find the linear closed-form solution $\hat{\mathbf{x}}_{W L S}$, which minimizes the objective function $J_{W L S}(\boldsymbol{\theta})$. It can be shown that $\hat{\mathbf{x}}_{W L S}$ can be obtained from (16) as follows:

$$
\hat{\mathbf{x}}_{W L S}=\left(\mathbf{A}^{T} \mathbf{W} \mathbf{A}\right)^{-1} \mathbf{A}^{T} \mathbf{W b} .
$$

The WLS method is usually chosen in practice due to its easy implementation and higher computational efficiency.

\section{Hybrid GA - NM method}

In this section, a new hybrid genetic algorithm is presented, which combines the GA, with powerful global-search abilities, with well-known direct local search NM method. The proposed hybridization is performed with the aim to simultaneously improve the convergence speed and the accuracy of the obtained solutions. In this way, the procedure of the corresponding GA and local search NM method are presented in the following subsections.

\section{Genetic algorithm}

The GA is one of the most powerful optimization methods based on the mechanics of natural evolution [5], which can be successfully applied to solve the NLS minimization problems. The minimization problem in Eq. (3) can be modified by introduction of bound-constraints, which can be written as:

$$
\min _{\mathbf{x}^{l} \leq \mathbf{x} \leq \mathbf{x}^{h}} J_{N L S}(\mathbf{x}),
$$

in which $\mathbf{x}$ is a vector of decision variables, $\mathbf{x}^{l}$ and $\mathbf{x}^{h}$ are the lower and upper bounds of $\mathbf{x}$, respectively.

GA evolves a population of individuals where each individual represents a candidate solution for a given optimization problem. Each solution is usually coded as a binary string called a chromosome. Main operations applied to chromosomes of the population are selection, crossover, and mutation.

Roulette wheel selection is one of the traditional selection techniques in GA. In this technique, all the individuals in the population are placed on the roulette wheel according to their objective function $J_{N L S}(\mathbf{x})$, in which individuals with the smaller objective function in the current generation are reproduced to the next generation. The selection probability $P_{i}$ of the $i$ th chromosome is computed as follows:

$$
P_{i}=\frac{F_{i}}{\sum_{j=1}^{N_{p}} F_{j}}, \quad i \in\left\{1, \ldots, N_{p}\right\}
$$

where $N_{p}$ is population size and $F_{i}=J_{N L S}(\mathbf{x})$ is the corresponding fitness value. The cumulative probability $C_{i}$ of the $i^{\text {th }}$ chromosome is obtained as follows:

$$
C_{i}=\sum_{j=1}^{N_{p}} F_{j}
$$

Based on a randomly generated nonzero floating-point number $r \in\left[\begin{array}{ll}0 & 1\end{array}\right]$ for each individual, the chromosome is selected if $C_{i-1}<r \leq C_{i}, i \in\left\{1,2, \ldots, N_{p}\right\}$ and $C_{0}=0$.

The crossover operator is applied in order to create new chromosomes for the next generation. Two random crossover points, $c_{1}$ and $c_{2}$, are chosen along the chromosomes. Then, the chromosome parts between crossover points are exchanged and two new chromosomes are created as shown in Fig.2.

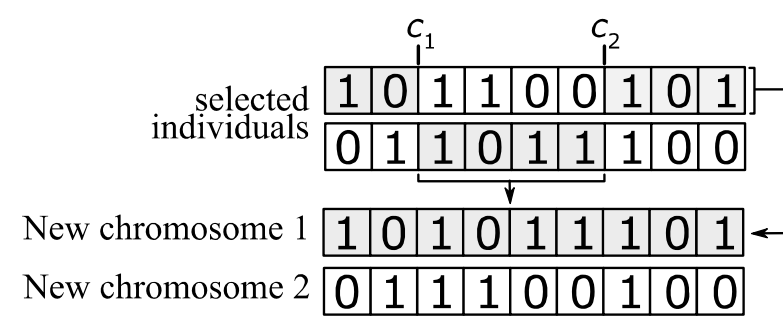

Figure 2. Two point crossover

Finally, the mutation process selects a random variable of a random individual and negates the bit in order to introduce new unexplored solutions into the search space and to overcome trapping in local minima.

The process of selection, crossover and mutation continues for a fixed number of generations or until the fitness of the best and average individual becomes close to the global optimum.

\section{Nelder-Mead method}

The Nelder-Mead simplex method is one of the most widely used local direct search methods for finding a local minimum without using the gradient information of the objective function [6].

In the NM simplex method, a simplex is a geometrical figure consisting of $n+1$ points $\left\{\mathbf{x}_{i}: 1 \leq i \leq n+1\right\}$ as vertices in $\mathbb{R}^{n}$. The main concepts of the NM method include operations on the initial simplex $\mathrm{S}:=\left\{\mathbf{x}_{1}, \mathbf{x}_{2}, \mathbf{x}_{3}\right\}$ in $\mathbb{R}^{2}$, which are illustrated in Fig.3.

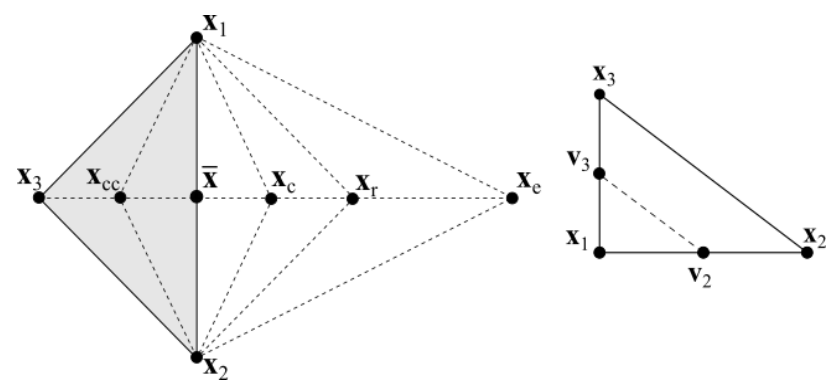

Figure 3. Operations of Nelder-Mead method for an optimization in $\mathbb{R}^{2}$

As shown in Fig.3, the initial simplex is bounded by a solid line and its worst vertex is denoted by $\mathbf{x}_{3}$, where $\mathbf{x}_{r}, \mathbf{x}_{e}, \mathbf{x}_{c}$ and $\mathbf{x}_{c c}$ are the vertices of reflection, expansion, outside and inside contraction, respectively. In order to define the vertices of the simplex for the next iteration, the centroid $\overline{\mathbf{x}}$ of the line segment connecting the two best vertices $\mathbf{x}_{1}$ and $\mathbf{x}_{2}$ is also 
illustrated in Fig.3. The result of each iteration is a new vertex, which replaces the current worst vertex $\mathbf{x}_{3}$, or a set of $n$ new points (if a shrinkage is performed), which together with $\mathbf{x}_{1}$ form a new simplex for the next iteration. With these operations, the simplex is successfully improved at the end of each iteration step. In this way, the initial simplex moves away from the worst vertex towards the local optimum, for which the objective function value at the vertices becomes smaller as the iteration progresses.

A single iteration of the NM local direct search method is described in following steps:

Step 1. Initialization. Starting from the initial vertex $\mathbf{x}_{1}$ found by GA algorithm, the NM method determines the remaining $n$ vertices $\left\{\mathbf{x}_{i+1}: 1 \leq i \leq n\right\}$ in the search space as follows:

$$
\mathbf{x}_{i+1}:=\mathbf{x}_{1}+\lambda \mathbf{e}_{i}, i=1, \ldots, n,
$$

where $\mathbf{e}_{i}$ is the unit vector of the $i^{\text {th }}$ coordinate axis and $\lambda \in \mathbb{R}$ is initial step size commonly used as $\lambda=1$.

Step 2. Sorting. Evaluate the objective function value at each vertex and sort the $n+1$ vertices in ascending order, such that:

$$
f\left(\mathbf{x}_{1}\right) \leq f\left(\mathbf{x}_{2}\right) \leq \ldots \leq f\left(\mathbf{x}_{n+1}\right) .
$$

Step 3. Simplex generation. For the corresponding vertices $\left\{\mathbf{x}_{i}: 1 \leq i \leq n+1\right\}$ the new simplex is formed using four possible geometric operations such as:

a) Reflection. The reflection point $\mathbf{x}_{r}$ is generated by reflecting the vertex $\mathbf{x}_{n+1}$, with the highest objective function value as follows:

$$
\mathbf{x}_{r}:=\overline{\mathbf{x}}+\alpha\left(\overline{\mathbf{x}}-\mathbf{x}_{n+1}\right),
$$

where $\overline{\mathbf{x}}$ is the centroid of the $n$ best vertices defined as:

$$
\overline{\mathbf{x}}:=\frac{1}{n} \sum_{i=1}^{n} \mathbf{x}_{i} .
$$

If $f\left(\mathbf{x}_{r}\right)<f\left(\mathbf{x}_{1}\right)$, the reflected point $\mathbf{x}_{r}$ is accepted and the method proceeds with the expansion; otherwise if $f\left(\mathbf{x}_{1}\right) \leq f\left(\mathbf{x}_{r}\right)<f\left(\mathbf{x}_{n}\right)$, replace $\quad \mathbf{x}_{n+1}$ with $\quad \mathbf{x}_{r} \quad$ and terminate the iteration.

b) Expansion. Expansion point is calculated in the direction of the reflection point as follows:

$$
\mathbf{x}_{e}=\overline{\mathbf{x}}+\beta\left(\mathbf{x}_{r}-\overline{\mathbf{x}}\right) .
$$

If $f\left(\mathbf{x}_{e}\right)<f\left(\mathbf{x}_{r}\right)$, a correct direction is found for minimization, replace the vertex $\mathbf{x}_{n+1}$ by $\mathbf{x}_{e}$ and terminate iteration; otherwise replace $\mathbf{x}_{n+1}$ with $\mathbf{x}_{r}$ and terminate iteration.

c) Contraction. After reflection, there are two possible contractions that are performed if $f\left(\mathbf{x}_{r}\right) \geq f\left(\mathbf{x}_{n}\right)$.

If $f\left(\mathbf{x}_{n}\right) \leq f\left(\mathbf{x}_{r}\right)<f\left(\mathbf{x}_{n+1}\right)$, an outside contraction point $\mathbf{x}_{c}$ is determined as follows:

$$
\mathbf{x}_{c}:=\overline{\mathbf{x}}+\gamma\left(\mathbf{x}_{r}-\overline{\mathbf{x}}\right)
$$

1. If $f\left(\mathbf{x}_{c}\right) \leq f\left(\mathbf{x}_{r}\right)$, replace $\mathbf{x}_{n+1}$ by $\mathbf{x}_{c}$ and terminate iteration; otherwise, perform shrinkage.

2. If $f\left(\mathbf{x}_{r}\right) \geq f\left(\mathbf{x}_{n+1}\right)$, an inside contraction point $\mathbf{x}_{c c}$ is obtained as follows:

$$
\mathbf{x}_{c c}:=\overline{\mathbf{x}}-\gamma\left(\overline{\mathbf{x}}-\mathbf{x}_{n+1}\right)
$$

If $f\left(\mathbf{x}_{c c}\right)<f\left(\mathbf{x}_{n+1}\right)$, replace $\mathbf{x}_{n+1}$ by $\mathbf{x}_{c c}$ and terminate the iteration; otherwise, perform shrinkage.

d) Shrinkage. The shrinkage is performed on vertices $\left\{\mathbf{x}_{i}: 2 \leq i \leq n+1\right\}$ to generate the simplex for the next iteration as follows:

$$
\mathbf{v}_{i}:=\mathbf{x}_{1}+\delta\left(\mathbf{x}_{i}-\mathbf{x}_{1}\right)
$$

For the NM method in $\mathbb{R}^{2}$, where the simplex is a triangle, $\alpha, \beta, \gamma$ and $\delta$ are real parameters that control reflection, contraction, expansion and shrinkage, respectively and these parameters are chosen as follows: $\alpha:=1, \quad \beta:=2, \quad \gamma:=0.5$, and $\delta:=0.5[6]$.

The iteration process of the NM method is repeated until the convergence criterion is satisfied, i.e.:

$$
\frac{1}{n+1} \sum_{i=1}^{n+1}\left\|\mathbf{x}_{i}^{(k)}-\mathbf{x}_{i}^{(k+1)}\right\|^{2} \leq \varepsilon,
$$

where $\mathbf{x}_{i}^{(k)}$ and $\mathbf{x}_{i}^{(k+1)}$ are the vertices in iteration $k$ and $k+1$, respectively and $\varepsilon$ is an arbitrarily small positive number.

\section{Cramer-Rao Lower Bounds}

In general, the CRLB provides the theoretical lower bound on the covariance matrix of any unbiased estimator [4]. The CRLB can be obtained using the inverse of the Fisher information matrix (FIM) $\mathbf{I}(\mathbf{x})$, which can be defined as:

$$
\begin{aligned}
\mathbf{I}(\mathbf{x})=E\left[\left(\frac{\partial \ln (f(\mathbf{r} \mid \mathbf{x}))}{\partial \mathbf{x}}\right)\left(\frac{\partial \ln (f(\mathbf{r} \mid \mathbf{x}))}{\partial \mathbf{x}}\right)^{T}\right] \\
=-E\left[\frac{\partial^{2} \ln (f(\mathbf{r} \mid \mathbf{x}))}{\partial \mathbf{x} \partial \mathbf{x}^{T}}\right],
\end{aligned}
$$

where is $E[\cdot]$ the expectation operator and $f(\mathbf{r} \mid \mathbf{x})$ is a probability density function that has the following form:

$$
\begin{aligned}
f(\mathbf{r} \mid \mathbf{x}) & =\frac{1}{(2 \pi)^{N / 2}|\mathbf{C}|^{1 / 2}} \\
& \cdot \exp \left(-\frac{1}{2}(\mathbf{r}-\mathbf{d}(\mathbf{x}))\right)^{T} \mathbf{C}^{-1}\left(-\frac{1}{2}(\mathbf{r}-\mathbf{d}(\mathbf{x}))\right),
\end{aligned}
$$

where $\mathbf{C}=\operatorname{diag}\left\{\sigma_{1}^{2}, \ldots . \sigma_{N}^{2}\right\}$ is $N$ dimensional covariance matrix.

Therefore, the elements of the Fisher information matrix:

$$
\mathrm{CRLB}=\mathbf{I}^{-1}=\frac{1}{|\mathbf{I}|}\left[\begin{array}{cc}
I_{y y} & -I_{x y} \\
-I_{y x} & I_{x x}
\end{array}\right],
$$

can be obtained as follows: 


$$
\begin{gathered}
I_{x x}=\sum_{i=1}^{N} \frac{\left(x-x_{l}\right)^{2}}{d_{l}^{2} \sigma_{i}^{2}}, \\
I_{x y}=I_{y x}=\sum_{i=1}^{N} \frac{\left(x-x_{l}\right)\left(y-y_{l}\right)}{d_{l}^{2} \sigma_{i}^{2}}, \\
I_{y y}=\sum_{i=1}^{N} \frac{\left(y-y_{l}\right)^{2}}{d_{l}^{2} \sigma_{i}^{2}} .
\end{gathered}
$$

Then, the relationship between the CRLB and the variance can be expressed as:

$$
E\left[(\hat{\mathbf{x}}-\mathbf{x})(\hat{\mathbf{x}}-\mathbf{x})^{T}\right] \geq \operatorname{CRLB}(\mathbf{x})=\operatorname{tr}\left\{\mathbf{I}(\mathbf{x})^{-1}\right\},
$$

where $\hat{\mathbf{x}}$ is estimated vector of $\mathbf{x}$ and $\operatorname{tr}\{\cdot\}$ is the trace operator.

\section{Simulation results}

In this section, the localization performance of the hybrid GA-NM method is evaluated and compared with the closedform WLS method, GA and CRLB. In the simulation environment, four receivers with known coordinates $[500,-500]^{T} \mathrm{~m}, \quad[500,500]^{T} \mathrm{~m}, \quad[-500,500]^{T} \mathrm{~m}, \quad$ and $[-500,-500]^{T} \mathrm{~m}$ are involved in the localization process. It is assumed that the target is located at $[100,100]^{T} \mathrm{~m}$. Then, the localization performance is evaluated through root mean square error (RMSE) defined as:

$$
R M S E=\sqrt{\frac{1}{N} \sum_{n=1}^{N}\|\hat{\mathbf{x}}(n)-\mathbf{x}\|_{2}^{2}},
$$

where $\mathbf{x}$ and $\hat{\mathbf{x}}(n)$ are the true and estimated positions of the target, respectively, and $N=200$ is a number of Monte Carlo simulation runs.

The cumulative distribution functions (CDFs) of localization errors based on the hybrid GA-NM, GA and WLS methods are compared to evaluate the localization performance. Simulations are performed with different levels of SNR, SNR $=10 \mathrm{~dB}$ and $\mathrm{SNR}=40 \mathrm{~dB}$, respectively.

The CDFs of localization errors using the considered algorithms are illustrated in Fig.4, for SNR level set to 10dB.

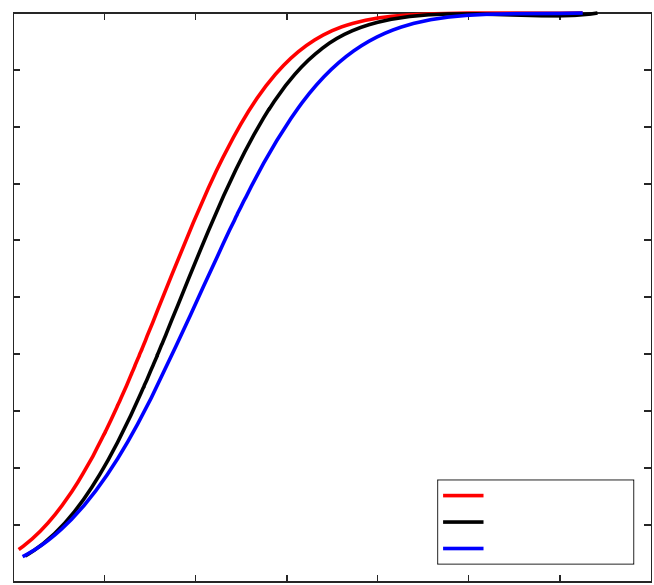

Figure 4. $C D F s$ of the localization error for $\mathrm{SNR}=10 \mathrm{~dB}$
From the results presented in Fig.4, it can be concluded that the hybrid GA-NM method has a superior performance in comparison to the other considered algorithms.

Fig.5 depicts CDFs of previously considered algorithms for the case when the $\mathrm{SNR}=40 \mathrm{~dB}$.

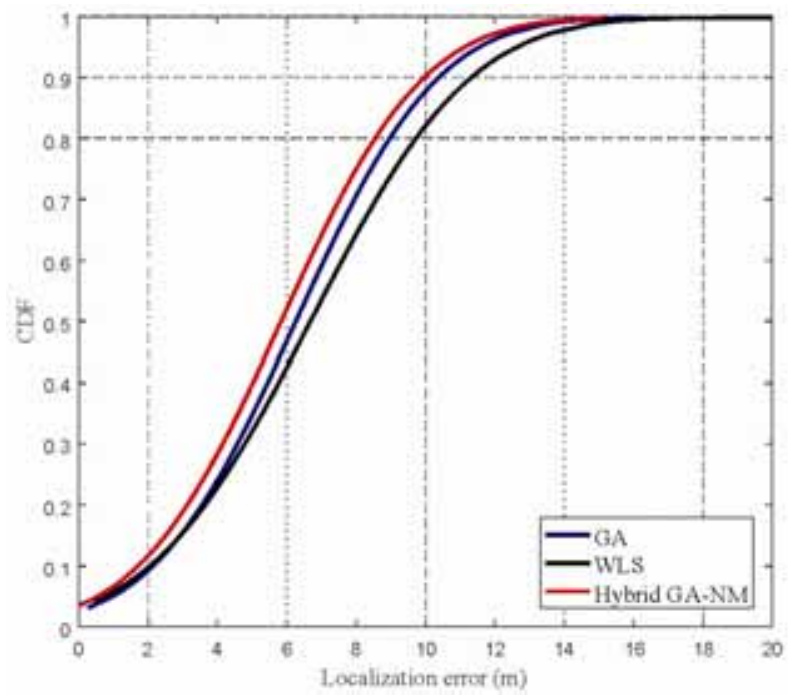

Figure 5. $\mathrm{CDF}$ s of the localization error for $\mathrm{SNR}=40 \mathrm{~dB}$

From Fig.5, it is observed that in the case when the SNR is larger the CDFs of hybrid GA-NM method has outperform the both GA and WLS methods.

Comparing the numerical results from Figures 4 and 5, respectively, it can be observed that hybrid GA-NM method has better localization accuracy then the both GA and WLS methods, especially in the high SNR levels.

Finally, Fig. 6 shows the RMSE as the function of the SNR for the hybrid GA-NM, GA and the WLS methods.

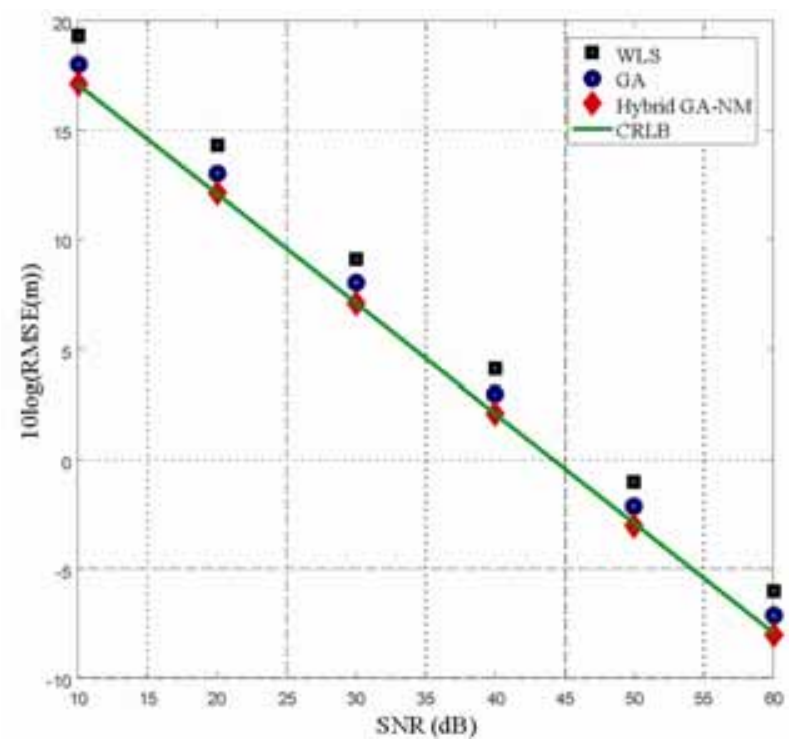

Figure 6. Comparison of RMSE versus SNR levels

From the results in Fig.6, it is observed that proposed hybrid GA-NM method reaches the CRLB for wide range of SNR, implicating the hybrid GA-NM as a robust method in different noisy measurement environments, outperforming both GA and WLS methods.

\section{Conclusion}

In this paper, the TOA localization problem based on the noisy measurements is formulated as the WLS and NLS estimation problem. To efficiently solve this localization 
problem a novel hybrid algorithm, based on the GA and NM method is introduced in this paper. Simulation results show that the proposed hybrid GA-NM method outperforms the both GA and WLS methods and can achieve higher localization accuracy over a wide range of SNR values.

\section{References}

[1] FIGUEIRAS,J., FRATTASI,S.: Mobile Positioning and Tracking, John Wiley \& Sons, United Kindom, 2010.

[2] CHALISE,B., ZHANG,Y., AMIN,M., HIMED,B.: Target localization in a multi-static passive radar system through convex optimization, Signal Processing, 2014, 102, pp. 207-215.
[3] EINEMO,M., SO,H.C.: Weighted least squares algorithm for target localization in distributed MIMO radar, Signal Processing, 2015, 115, pp. 144-150.

[4] LAARAIEDH,M., AVRILLON,S., UGUEN,B.: Cramer-Rao lower bounds for nonhybrid and hybrid localisation techniques in wireless networks, European Transactions on Telecommunications, 2012, 23, pp. 268-280.

[5] NOROUZI,A., ZAIM,A.H.: Genetic algorithm application in optimization of wireless sensor networks, The Scientific World Journal, 2014.

[6] GAO,F.,LIXING,H.: Implementing the Nelder-Mead simplex algorithm with adaptive parameters, Computational Optimization and Applications, 2012, 51, pp. 259-277.

\title{
Hibridna optimizaciona metoda bazirana na genetskom algoritmu za tačno određivanje nepoznate lokacije predajnika
}

\begin{abstract}
U ovom radu, prikazan je TOA (Time of Arrival) model pozicioniranja radi određivanja nepoznate lokacije predajnika. Definisan je kriterijum optimalnosti - funkcija cilja, koja predstavlja sumu kvadrata greške pozicioniranja. Za rešavanje postavljenog optimizacionog modela primenjena je nova metoda GA-NM, koje je bazirana na hibridizaciji Genetskog algoritma i Nelder-Mead metode. Predložena hibridna metoda na efikasan način kombinuje globalnu i lokalnu pretragu datih algoritama kako bi se poboljšale optimizacione performanse i tačnost rešenja. Pored ovoga, u radu je izvedena i Kramer-Rao donja granica CRLB (Cramer-Rao Lower Bound) varijanse procene nepoznate lokacije predajnika za TOA metodu pozicioniranja. Rezultati simulacije pokazuju da predložena hibridna GA-NM metoda postiže značajano poboljšanje performansi u odnosu na postojeće metode.
\end{abstract}

Ključne reči: predajnik, pozicioniranje, optimizacija, genetski algoritam, hibridna metoda.

\section{Гибридный метод оптимизации на основе генетического алгоритма для точного определения неизвестного местоположения передатчика}

\begin{abstract}
В этой работе показана модель позиционирования МП (время прибытия) для определения неизвестного местоположения передатчика. Определён критерий оптимальности - целевая функция, которая представляет собой сумму квадрата ошибки позиционирования. Для решения модели оптимизации множеств был использован новый метод GA-NM, основанный на гибридизации Генетического алгоритма и метода Нелдера-Мида. Предложенный гибридный метод эффективно сочетает глобальный и локальный поиск с заданными алгоритмами для повышения производительности оптимизации и точности решения. В дополнение к этому, нижний предел Крамера-Рао дисперсии CRLB (нижняя граница Крамера-Рао) оценивается для неизвестного местоположения передатчика для метода определения позиционирования МП. Результаты моделирования показывают, что предложенный гибридный метод GA-NM достигает значительного улучшения производительности по сравнению со существующими методами.
\end{abstract}

\section{Méthode hybride d'optimisation basée sur l'algorithme génétique pour la détermination précise de la location inconnue de l'émetteur}

\footnotetext{
Dans ce papier on a présenté le TOA ( Time of arrival) modèle de positionnement pour la détermination de la location inconnue de l'émetteur. On a défini le critère d'optimalité - fonction de but qui représente la somme des carrés de l'erreur de positionnement. Pour résoudre le modèle d'optimisation on a appliqué la nouvelle méthode GA-NM qui est basée sur la hybridation de l'algorithme génétique et la méthode Nelder-Mead. La méthode hybride proposée combine efficacement la recherche globale et locale des algorithmes donnés pour améliorer les performances d'optimisation et l'exactitude de la solution. En outre on a dérivé aussi la basse limite de Cramer-Rao CRLB ( Cramer-Rao Lower Board ) de la variante d'estimation de la location inconnue de l'émetteur pour la méthode TOA de positionnement. Les résultats de simulation démontrent que la méthode hybride proposée GA-NM effectue une amélioration signifiante des performances par rapport aux méthodes existantes.
} 